
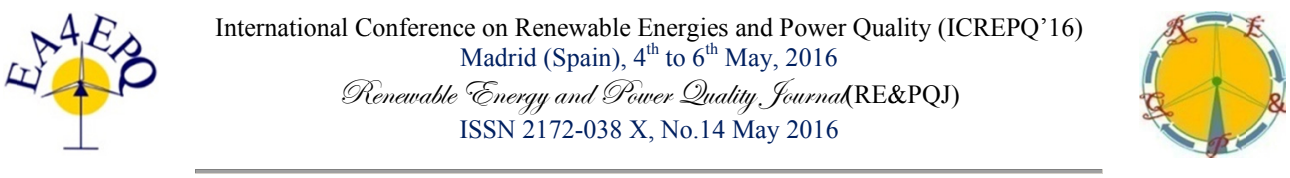

\title{
Natural ventilation strategies for cooling purposes in the rural vernacular architecture of Cyprus
}

\author{
D. Demosthenous ${ }^{1}$, A. Michael $^{2}$, M. Philokyprou ${ }^{3}$ \\ ${ }^{1}$ Department of Civil and Environmental Engineering, Faculty of Engineering, University of Cyprus, \\ demosthenous.d@gmail.com \\ ${ }^{2}$ Lecturer, Department of Architecture, Faculty of Engineering, University of Cyprus, aimilios@ucy.ac.cy \\ ${ }^{3}$ Assistant Professor, Department of Architecture, Faculty of Engineering, University of Cyprus, \\ philokyprou.maria@ucy.ac.cy
}

\begin{abstract}
The reuse of vernacular dwellings is a sustainable approach, not only because it leaves a small ecological footprint, as opposed to the construction of new buildings, but also because the passive bioclimatic design features of vernacular buildings result in better indoor thermal comfort and in the reduction of energy consumption. This study investigates natural ventilation strategies for cooling purposes in traditional buildings, using exclusively the technique of cross ventilation. The main objective of the present paper is to quantitatively investigate the effectiveness of various natural ventilation strategies, i.e., daytime ventilation, full-day (24-hour) ventilation and night ventilation, in the rural vernacular architecture of Cyprus. In this framework, a field research study was conducted in a representative traditional dwelling in the village of Kapedes, Nicosia, in order to assess the aforementioned ventilation strategies during the hot, summer season. The results show that night ventilation is the most effective strategy for passive cooling in traditional dwellings during the hot summer period, compared to the two other ventilation strategies. The analysis provides evidence that night ventilation reduces indoor temperatures and, consequently, improves the indoor thermal environment of the following day.
\end{abstract}

\section{Key words}

natural ventilation strategies, thermal comfort, cross ventilation, Mediterranean climate, vernacular architecture

\section{Introduction}

The vernacular architecture of Cyprus is an excellent example of bioclimatic architecture since it incorporates a series of environmental features [1]. Indoor thermal comfort during the summer season is the result of a number of passive cooling design principles such as the high thermal building materials, the architectural layout, the appropriate shading of the building envelope, natural ventilation and proper vegetation [2]. Natural ventilation is one of the most important cooling strategies of vernacular architecture in Cyprus. Its efficiency depends on the occupants' habits and, more specifically, on windowopening behavioural patterns [3]. Generally speaking, daytime ventilation is most appropriate for mild climates, where air temperature and humidity of the external environment fall within comfort limits. However, in hot climates, night ventilation is recommended as an indirect technique that improves indoor thermal conditions during the following day [4]. The effectiveness of night ventilation depends upon the diurnal temperature range of the location and the thermal mass of the building envelope [5].

The effectiveness of the thermal inertia of the building envelope in stabilizing the indoor temperature, regardless of outdoor temperature fluctuations during the day, is well documented in other field studies $[1,3,6]$. More specifically, the studies conducted on the vernacular architecture of Cyprus [1,3] indicate that thermal mass delays the appearance of the maximum indoor air temperature in relation to that of the external environment. However, the studies in question have not examined quantitatively the heat storage capabilities of the building elements, e.g. the walls. This analysis is achieved by establishing the time $\operatorname{lag}(\varphi)$ factor which is defined as the time delay between the peak outside temperature and the peak inside temperature, within a certain period of time [7].

The present study evaluates the effectiveness of three different ventilation cooling strategies, i.e., daytime, fullday (24-hours) and night ventilation, based on the findings of a field study undertaken during the summer period of 2015 in a representative vernacular dwelling, located in a semi-mountainous region of Cyprus. The quantitative assessment of natural ventilation strategies for cooling in residential vernacular architecture of 
Cyprus is carried out through a comparative assessment of air temperature, time lag and thermal comfort (operative temperature).

\section{Research methodology}

The building under investigation (Fig. 1) is located at the centre of Kapedes village, Nicosia (climatic zone 03 semi-mountainous region) which is characterized by narrow streets and a continuous building system. The majority of the traditional dwellings in the neighbourhood of the building under study are conserved to their original form. The traditional building selected incorporates most of the environmental characteristics of vernacular architecture of Cyprus which facilitates a more accurate qualitative and quantitative assessment.

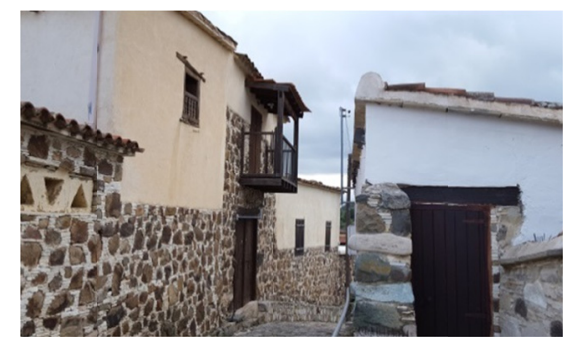

Fig. 1. Exterior view of the building under investigation

The dwelling is a two storey building which consists of a semi-open space called iliakos (Fig. 2a), serving as an entrance, as well as of an intermediate space between the street and the house, a large double space room, called dichoro (Fig. 2b), other auxiliary rooms on the ground level and two bedrooms on the second level.
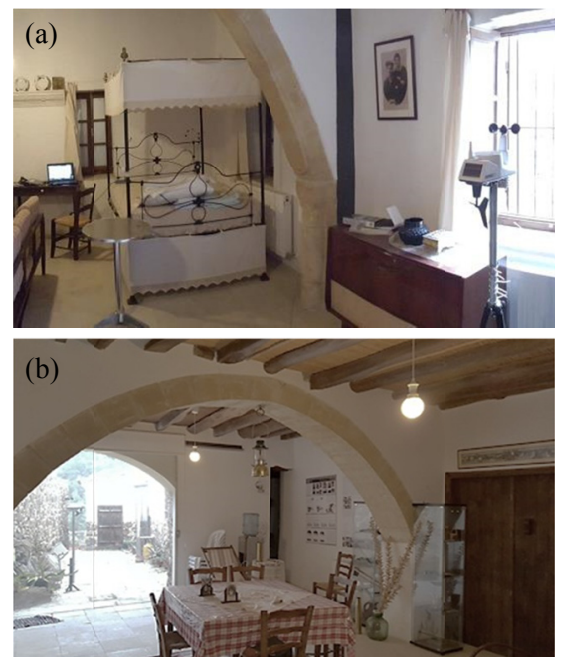

Fig. 2. Interior views of (a)iliakos and (b)dichoro

The walls of the building are load bearing, constructed of local stone and adobes and plastered internally with gypsum plaster. They are $50 \mathrm{~cm}$ thick at ground level and about $40-45 \mathrm{~cm}$ thick on the first floor level. The inclined roofs are made of timber, reeds and clay and are covered by tiles. The house has recently been restored to its original form, preserving almost all its authentic characteristics.
The field monitoring was carried out during the summer period of 2015 . Therefore, the potential of natural ventilation for cooling purposes was the only parameter examined. During the investigated period, specific environmental parameters were recorded in order to scientifically document the effect of natural ventilation in vernacular architecture of Cyprus. Measurements were taken in dichoro, which comprises the main room of traditional dwellings in Cyprus. During the field study, the door between the dichoro and the iliakos remained closed in order to create a controlled indoor environment.

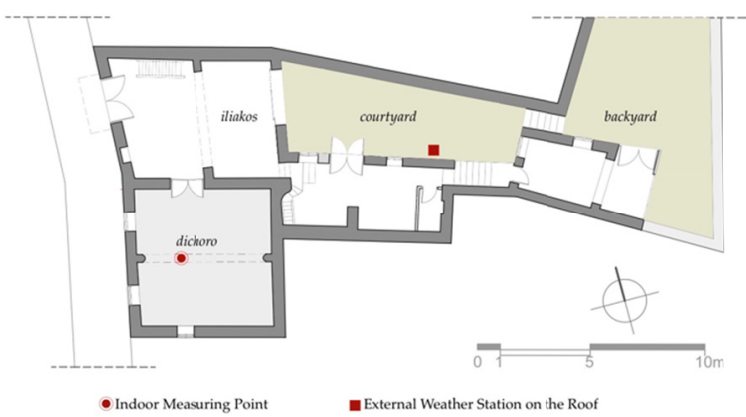

Fig. 3. Plan view of the case study

Initially, the case study was investigated without any form of ventilation between the $7^{\text {th }}$ and $9^{\text {th }}$ of July, so that reference values could be recorded. Afterwards, the three ventilation strategies were examined during the period between the $25^{\text {th }}$ of July and the $2^{\text {nd }}$ of August. In order to ensure high rate of air exchange, all three windows of the room remained wide open during field measurements of ventilation strategies. The different strategies were applied sequentially (each strategy investigated for two consecutive days) in the following order: daytime ventilation, full-day (24-hour) ventilation and night ventilation. During daytime ventilation, the windows remained open from $07: 00 \mathrm{~h}$ to $21: 00 \mathrm{~h}$ and were closed from 21:00h to $07: 00 \mathrm{~h}$, while, during night ventilation the windows remained open from 21:00h to $07: 00 \mathrm{~h}$ and were closed from 07:00h to 21:00h. Between each ventilation strategy, a meantime period intervened, during which the openings were closed in order for the space to return to its initial thermal condition, i.e. 34 hours between daytime and full-day (24-hour) ventilation and 38 hours between full-day (24-hour) ventilation and night ventilation.

The indoor environmental parameters measured were the following: air temperature, air velocity and globe temperature. The measurements were taken at fiveminute intervals, using appropriate measurement equipment, i.e. ELR610M - Heat Shield Base Module and a Vaisala WINDCAP ${ }^{\circledR}$ Ultrasonic Wind Sensor WMT700. The equipment was placed at a height of $75 \mathrm{~cm}$ above floor level, at a central point of the dichoro. At the same time, a wireless weather station Vantage Pro 2 Plus was installed on the roof of the traditional dwelling which recorded the climatic conditions of the immediate environment. The recorded temperatures of both the indoor and outdoor environment are used for a comparative evaluation of the cooling potential of each ventilation strategy. Furthermore, temperature sensors 
were installed on the inside and outside surface of the south façade of the case study in order to calculate the time lag factor using the following equation:

$$
\boldsymbol{\varphi}=\boldsymbol{\tau}\left(\boldsymbol{T}_{\boldsymbol{s i}_{\text {max }}}\right)-\tau\left(\boldsymbol{T}_{\boldsymbol{s e}_{\text {max }}}\right)(1)
$$

where $\tau\left(\mathrm{T}_{\mathrm{si} \max }\right)$ is the exact time of peak temperature of the inner surface and $\tau\left(\mathrm{T}_{\text {se } \max }\right)$ is the time of peak temperature of the external wall for a particular day [7].

Thermal comfort is assessed using the Adaptive Comfort Standard (ACS) which is incorporated in ASHRAE 55 [8]. The principle of the ACS is based on the fact that the occupants of naturally ventilated spaces have different expectations of thermal comfort than those of technically supported indoor spaces, due to their adaptation to outdoor conditions. The Adaptive Comfort Standard was developed by de Dear \& Brager [9], after a number of field research studies at a global scale. The operative temperature, in the present study, is taken to be the mean value of air temperature and mean radiant temperature. The acceptable indoor operative temperatures are determined using the $80 \%$ and $90 \%$ acceptability limits, calculated as a moving average of mean daily outdoor air temperature, using a seven-day moving average. This refers to the standard, i.e. the prevailing mean outdoor temperature. It is worth mentioning that, indoor air velocity, which is a crucial parameter for cooling, was relatively small in all cases and was thus, deemed negligible.

\section{Results and discussion}

\section{A. Contribution of ventilation as a cooling strategy}

The cooling effect provided through ventilation is mainly documented by air temperature and velocity. The registered indoor air velocity, in the monitoring in question, was rather low in all cases, of about $0.01 \mathrm{~m} / \mathrm{s}$. This may be attributed to the narrow streets and the rather dense fabric of the traditional core of the village. The positive contribution of natural ventilation is evaluated by comparing indoor and outdoor air temperaturesand it is shown in figures 4 and 5. The shaded area in Fig. 5 represents the period when the windows were open along with an annotation of the cooling strategy applied.

In the beginning, the space under study was examined without any natural ventilation (Fig 4.). During those three days of lack of ventilation, the peak indoor air temperatures were recorded approximately 5 hours after the respective outdoor ones. The particular time delay of indoor air temperature is due to the thermal storage in the thermal mass of the building envelope. Furthermore, the temperature fluctuation in dichoro was recorded to be stable, i.e. $1.2^{\circ} \mathrm{C}$, regardless of the fluctuation in the external environment i.e. $9.7^{\circ} \mathrm{C}$. Therefore, the positive contribution of the thermal inertia of the building envelope in stabilizing the internal temperature has been established.

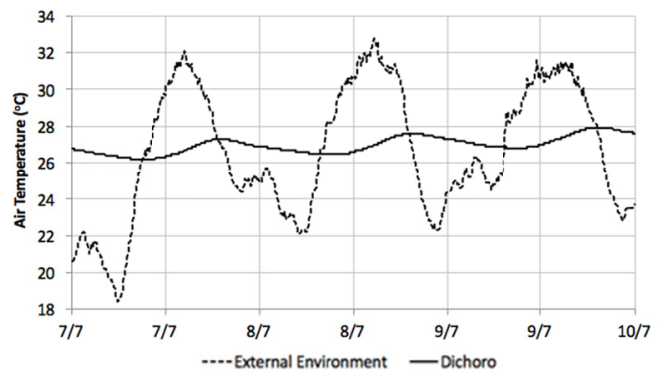

Fig. 4. Air temperatures for the period without ventilation

In the case of daytime ventilation (Fig. 5), the daily indoor air temperature follows the pattern of the external environment, while nocturnal indoor air temperature retains high values. More specifically, the peak indoor air temperature is $0.6^{\circ} \mathrm{C}$ lower than the outdoor one. Additionally, mean nocturnal indoor air temperature is $5.8^{\circ} \mathrm{C}$ above the respective mean of the external environment. The rapid increase of air temperature observed when the windows closed (21:00h), is attributed both to the heat stored in the thermal mass of the building envelope during daytime, as well as to the heat retained in the interior of dichoro during the night-time, when lower ambient temperature is registered.

In the case of full-day (24-hour) ventilation, the temperature of the indoor space follows the air temperature profile of outdoors, during both day and night. In particular, the peak indoor air temperature is $0.4^{\circ} \mathrm{C}$ lower than the outdoor one, while, average indoor air temperature during night-time is $2.7^{\circ} \mathrm{C}$ above outdoor air temperature. The difference of the nocturnal average between dichoro and external environment is lower in the strategy of full-day (24-hour) ventilation than in daytime ventilation strategy. Thus, it has been proven that the strategy of full-day (24-hour) ventilation improves indoor temperatures during the night compared to daytime ventilation.

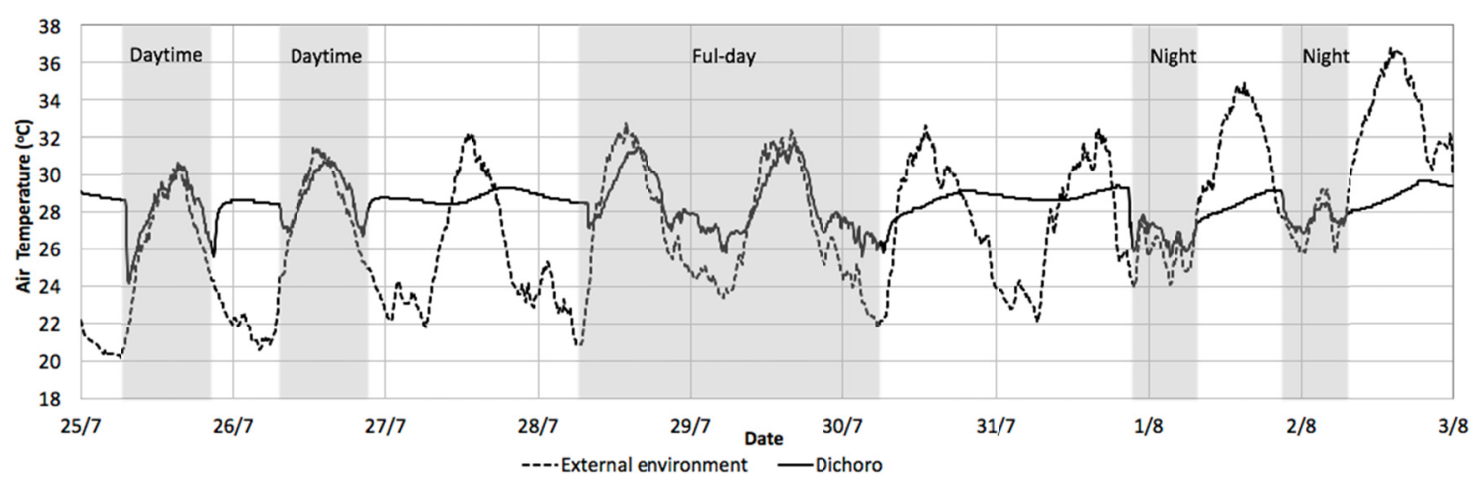

Fig. 5. Air temperatures recorded in different ventilation strategies 
The strategy of night ventilation provides lower nocturnal indoor air temperature compared to the two previous strategies. More specifically, indoor air temperatures during night follow closely the respective temperatures of the outdoor environment, with mean indoor air temperature being $0.7^{\circ} \mathrm{C}$ lower than that of the outdoor environment. The peak indoor air temperature is $29.7^{\circ} \mathrm{C}$, which is much lower than the temperature recorded during the application of daytime and full-day (24-hour) ventilation strategies. Additionally, the peak indoor air temperature delays approximately 6 hours in comparison to the peak temperature of the external environment. Night ventilation has a positive impact on the indoor space as it extracts heat from the thermal mass of the building envelope.

Furthermore, the thermal inertia of the building envelope for each ventilation strategy is determined through the factor of time lag (Table I).

Table I. - Mean time lag for each ventilation strategy

\begin{tabular}{cc} 
Strategy of Ventilation & Mean time lag (h) \\
\hline \hline No ventilation & $5: 20$ \\
\hline Daytime & $1: 50$ \\
\hline Full-day (24-hours) & $2: 20$ \\
\hline Night-time & $4: 40$
\end{tabular}

In particular, time lag is calculated as an average value for each strategy. It is observed that, mean time lag increases from daytime to night-time ventilation, which is in accordance with the previous assessment of air temperature. In the strategy of full-day (24-hour) ventilation, the indoor peak temperature occurs $0.30 \mathrm{~h}$ later compared to the peak temperature of daytime ventilation, due to the positive contribution of night ventilation that is incorporated in the full-day strategy. Night ventilation exhibits, as expected, significantly wider mean time lag of 4:40h compared to all the other strategies. However, nighttime ventilation has slightly narrower mean time lag in comparison with the period with no ventilation, which is $5: 20 \mathrm{~h}$. The most protected indoor environment during the period of no ventilation, i.e. no interaction with the external environmental conditions, led to the delay of heat transfer in the interior of the building. Consequently, it has been made evident that night ventilation takes full advantage of the thermal inertia of the building envelope in relation to the two other ventilation strategies.

\section{B. Evaluation of thermal comfort}

Thermal comfort for the period of no ventilation and for the three ventilation strategies is evaluated in figures 6 and 7 respectively. The comfort zone for both graphs was set for thermal environmental conditions acceptable to at least $80 \%$ and $90 \%$ of the occupants within dichoro. During the period of no ventilation, the lower acceptability limits for both $80 \%$ and $90 \%$ are between $22.3-22.6^{\circ} \mathrm{C}$ and 23.3 $23.6^{\circ} \mathrm{C}$ respectively. The corresponding upper limits vary from $29.3^{\circ} \mathrm{C}$ to $29.6^{\circ} \mathrm{C}$ for $80 \%$ and from $28.3^{\circ} \mathrm{C}$ to $28.6^{\circ} \mathrm{C}$ for $90 \%$.The shaded area of Fig. 7 represents the period in which the windows were open for each case, followed by an annotation of the strategy applied. The thermal comfort zone in Fig. 7 ranges from $22.4-23.1^{\circ} \mathrm{C}$ to $29.4-30.1^{\circ} \mathrm{C}$ for $80 \%$ acceptability and from $23.4-24.1^{\circ} \mathrm{C}$ to $28.4-29.10^{\circ} \mathrm{C}$ for $90 \%$ acceptability.

In the case of no natural ventilation, operative temperatures fall within the required comfort zone. Therefore, the high thermal mass of the building envelope (Table I), ensures thermal comfort in the indoor environment without the application of any ventilation. However, operative temperatures increased slightly during the three days of the period under study. Specifically, the peak operative temperatures increased by $1.1^{\circ} \mathrm{C}$ from $7^{\text {th }}$ to $9^{\text {th }}$ of July.

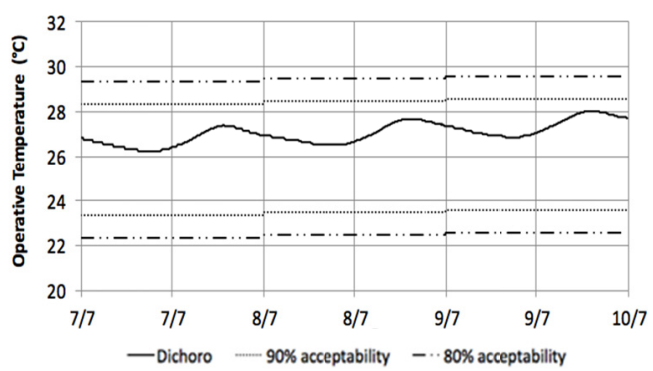

Fig. 6. Operative temperatures for the period without ventilation

In the case of daytime ventilation, diurnal operative temperatures exceed the upper acceptability limits, whereas nocturnal ones remain below the 90\% upper limit. The peak operative temperatures are approximately $1.7^{\circ} \mathrm{C}$ above the limit of $90 \%$. Additionally, the operative temperatures exceed the upper acceptability limits for $12 \%$ of the time of the experimental period of daytime ventilation, in the case of $80 \%$ acceptability, and, $31 \%$ in the case of $90 \%$ acceptability. The operative temperatures begin to fall within the comfort zone in afternoon hours, shortly after 18:00h. The rapid increase of indoor operative temperature after $21: 00 \mathrm{~h}$ is in accordance with the corresponding increase of relative air temperature.

As shown in figure 7, the strategy of full-day (24-hour) ventilation exhibits high diurnal temperature range of approximately $5^{\circ} \mathrm{C}$. This is related to the fact that indoor temperatures follow closely the outdoor weather conditions. Subsequently, the operative temperature exceeds the upper limits during daytime, while it falls within the limits during night-time. More specifically, operative temperatures exceed the upper acceptability limits of $80 \%$ for $27 \%$ of the time during the period of full-day (24-hour) ventilation and $44 \%$ in the case of $90 \%$ acceptability. It is noted that the exceeding periods of full-day (24-hour) ventilation are much higher than the respective ones in daytime ventilation. Higher outdoor air temperatures at that particular period contribute to this effect. During the period of full-day (24-hour) ventilation, peak operative temperatures are approximately $2^{\circ} \mathrm{C}$ above the limit of $90 \%$. Nevertheless, nocturnal operative temperatures are improved in relation to daytime ventilation as mean nocturnal operative temperatures are $1.4^{\circ} \mathrm{C}$ lower than the respective mean nocturnal operative temperatures during the daytime ventilation period. 


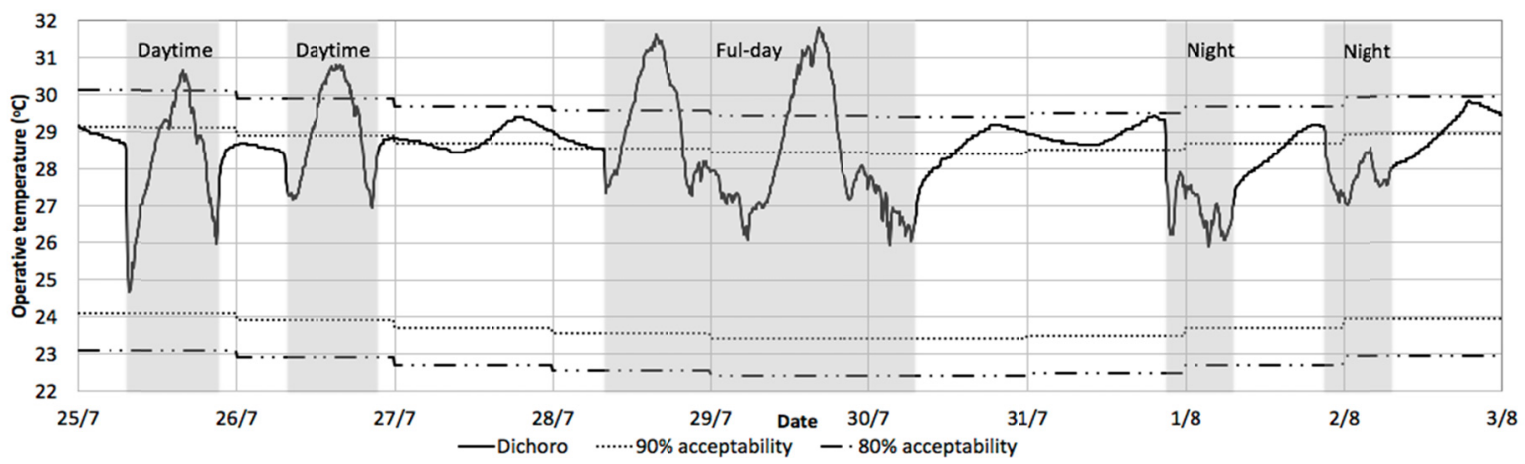

Fig. 7. Thermal comfort evaluation for different ventilation strategies

In the case of night ventilation, the measurements of nocturnal operative temperature are similar to the corresponding ones of full-day (24-hour) ventilation. However, in this case, diurnal operative temperature remains below the upper limit of $80 \%$, ensuring thermal comfort during hot midday hours. Moreover, operative temperatures exceed the upper acceptability limit of $90 \%$ only for $11 \%$ of the time during the period of night ventilation. Furthermore, peak operative temperatures are recorded at 19:00 which is approximately 3:30h after the corresponding peaks of the two previous ventilation strategies. Therefore, it becomes evident that night ventilation significantly reduces peak operative temperatures through the day and, in particular, during the morning hours in comparison to full-day and daytime ventilation, ensuring better thermal conditions, even with significantly higher outdoor air temperatures of 2.5 to $5.0^{\circ} \mathrm{C}$ at that particular time.

\section{Conclusions}

The present study has qualitatively shown that night ventilation has a positive contribution to the cooling effect of indoor spaces of the traditional dwelling during the hot summer period, ensuring thermal levels within the range of $80 \%$ acceptability limits of indoor operative temperature. The findings also show that night ventilation reduces peak temperatures during the next day and, in particular, during the morning and hot midday hours. On the other hand, the study provides evidence that both day-time and full-day ventilation strategies fail to ensure thermal comfort in the indoor environment. Both day-time and full-day ventilation exceed, to some extent, the upper acceptability limits, thus creating discomfort to the residents. Moreover, it is noted that night ventilation exhibits significantly wider mean time lag compared to all the other strategies, contributing positively to the thermal comfort during hot midday hours. Concerning the air velocity measurements, very low indoor air velocity was recorded during both day and night hours in all cases and thus its contribution cannot be safely assessed. The incorporation of fans will improve the effectiveness of natural ventilation.

The present study has established that night ventilation has a positive contribution to the cooling effect of indoor spaces during the hot summer period and has revealed that the occupants of vernacular dwellings in Cyprus ensure human comfort by using passive design principles. The above underlines the necessity of a deeper understanding of the occupant's role in ensuring the proper use of traditional dwellings as well as the ability of vernacular architecture to adapt to the surrounding environment.

\section{References}

[1] M. Philokyprou and A. Michael, "Evaluation of the Environmental Features of Vernacular Architecture. A Case Study in Cyprus", Proceedings EuroMed 2012, pp. 349-354.

[2] M. Philokyprou, A. Michael, St. Thravalou, "Assessment of the Bioclimatic Elements of Vernacular Architecture. The Historic Centre of Nicosia, Cyprus", Le Vies dei Mercanti XI Forume Internationalle di Studi, Proceedings, 2013, pp. 666-675.

[3] A. Michael, M. Philokyprou and C. Argyrou, "Documentation and Evaluation of the Positive Contribution of Natural Ventilation in the Rural Vernacular Architecture of Cyprus", Proceedings EuroMed 2014, pp. 310-320.

[4] M. Santamouris, "Ventilation for Comfort and Cooling: The State of the Art", in Building Ventilation: The State of the Art, London: Earthscan, 2006, pp. 217245

[5] E. Shaviv, A. Yezioroand, I. Capeluto, "Thermal mass and night ventilation as passive cooling design strategy", Renewable Energy, vol. 24, 200, pp. 445-452.

[6] D. Toe and T. Kubota, "Comparative assessment of vernacular passive cooling techniques for improving indoor thermal comfort of modern terraced houses in hothumid climate of Malaysia", Solar Energy, vol. 114, 2015, pp. 229-258.

[7] H. Asan, "Numerical computation of time lags and decrement factors for different building materials", Building and Environment, vol. 41, 2006, pp. 615-620.

[8] American Society of Heating, Refrigerating and AirConditioning Engineers, "ASHRAE Standard 55Thermal Environmental Conditions for Human Occupancy", Atlanta, Georgia, 2013.

[9] R. De Dear and G. Brager, "Thermal comfort in naturally ventilated buildings: revisions to ASHRAE Standard 55", Energy and Buildings, vol. 34, 2002, pp. 549-561. 